\title{
Infant intake of fatty acids from human milk over the first year of lactation
}

\author{
Leon R. Mitoulas ${ }^{1 *}$, Lyle C. Gurrin ${ }^{2}$, Dorota A. Doherty ${ }^{2}$, Jillian L. Sherriff ${ }^{3}$ and \\ Peter E. Hartmann ${ }^{1}$ \\ ${ }^{1}$ Biochemistry and Molecular Biology, School of Biomedical and Chemical Sciences, Faculty of Life and Physical \\ Sciences, The University of Western Australia, 35 Stirling Highway, Crawley WA 6009, Australia \\ ${ }^{2}$ Women and Infants Research Foundation and The University of Western Australia Department of Obstetrics and \\ Gynaecology, King Edward Memorial Hospital, Subiaco WA 6008, Australia \\ ${ }^{3}$ Department of Nutrition, Dietetics and Food Science, School of Public Health, Curtin University of Technology, \\ GPO Box U1987, Perth WA 6845, Australia
}

(Received 14 June 2002 - Revised 12 June 2003 - Accepted 11 July 2003)

\begin{abstract}
Despite the importance of human milk fatty acids for infant growth and development, there are few reports describing infant intakes of individual fatty acids. We have measured volume, fat content and fatty acid composition of milk from each breast at each feed over a $24 \mathrm{~h}$ period to determine the mean daily amounts of each fatty acid delivered to the infant from breast milk at 1,2, 4, 6, 9 and 12 months of lactation in five women. Daily ( $24 \mathrm{~h}$ ) milk production was 336.60 (SEM 26.21) and 414.49 (SEM 28.39) ml and milk fat content was 36.06 (SEM 1.37) and 34.97 (SEM 1.50) g/l for left and right breasts respectively over the course of the first year of lactation. Fatty acid composition varied over the course of the day (mean CV 14.3 (SD 7.7) \%), but did not follow a circadian rhythm. The proportions (g/100 g total fatty acids) of fatty acids differed significantly between mothers $(P<0.05)$ and over the first year of lactation $(P<0 \cdot 05)$. However, amounts $(\mathrm{g})$ of most fatty acids delivered to the infant over $24 \mathrm{~h}$ did not differ during the first year of lactation and only the amounts of $18: 3 n-3$, $22: 5 n-3$ and $22: 6 n-3$ delivered differed between mothers $(P<0 \cdot 05)$. Mean amounts of $18: 2 n-6,18: 3 n-3,20: 4 n-6$ and $22: 6 n-3$ delivered to the infant per $24 \mathrm{~h}$ over the first year of lactation were 2.380 (SD 0.980), 0.194 (SD 0.074), 0.093 (SD 0.031) and 0.049 (SD 0.021) g respectively. These results suggest that variation in proportions of fatty acids may not translate to variation in the amount delivered and that milk production and fat content need to be considered.
\end{abstract}

Fatty acids: Infant nutrition: Human milk lipids: Sampling protocols: Breast-feeding

It is now recognised that fat in human milk contributes significantly to the growth and development of the infant. Whilst fatty acids (FA) provide approximately $50 \%$ of the infant's energy requirements (Jensen et al. 1995), the long-chain polyunsaturated FA have been the focus of intense investigation for their roles in neonatal neural and visual development (Gibson et al. 1996; Innis et al. 2001) and immunological development (Isaacs et al. 1986). Despite the importance of these FA, Gibson \& Makrides (2000) noted that there is currently a lack of knowledge regarding infant FA intake, but concluded that we may need to rely on the composition of breast milk from wellnourished mothers as a guide to dietary recommendations for infants.

However, the determination of infant FA intake is not straightforward. Fat in human milk is variable, changing in content over the course of a feed (Hytten, 1954), during the day (Daly et al. 1993; Hartmann et al. 2000) and over the course of lactation (Butte et al. 1984;
Mitoulas et al. 2002). Furthermore, the FA composition itself can vary over the course of the day (Hall, 1979; Daly et al. 1993) and throughout the first year of lactation (Idota et al. 1991; Luukkainen et al. 1994; Makrides et al. 1995; Huisman et al. 1996), as well as from country to country (Read et al. 1965; Kneebone et al. 1985; Innis \& Kuhnlein, 1988). It is, therefore, imperative that all levels of variation are taken into account in order to accurately determine FA composition and ultimately the FA intake of the breast-fed infant.

We have used a sampling protocol similar to that of Hartmann et al. (1986): this takes into account changes in fat content of milk during a feed, differences between breasts and changes over the course of the day, and ensures minimum interference with infant feeding behaviour. Using this technique, we have determined the volume of milk removed by the infant, together with the fat content and FA composition of milk from each breast at each feed over a $24 \mathrm{~h}$ period at $1,2,4,6,9$ and 12 months of

Abbreviation: FA, fatty acid.
* Corresponding author: Dr L. R. Mitoulas, fax +6189380 1148, email Leon.Mitoulas@uwa.edu.au 
lactation for five breast-feeding women. These results were used to determine mean $24 \mathrm{~h}$ content of fat in milk and amounts of twenty-nine individual FA consumed by the infant from breast milk over $24 \mathrm{~h}$ periods from 1 to 12 months after birth.

\section{Methods}

\section{Subjects}

Healthy mothers and infants were recruited through the Australian Breastfeeding Association, Western Australian Branch, or from private healthcare centres. All mothers supplied written, informed consent to participate in the study, which was approved by the Human Research Ethics Committee, The University of Western Australia. Details of the subjects have been described previously (Cox et al. 1999; Kent et al. 1999). Briefly, all infants were fully breast-fed on demand for at least 4 months, with complementary solid foods being introduced between 4 and 6 months of age. All mothers maintained their own breast-feeding patterns throughout study periods and were consuming their own ad libitum diets. All study periods were within 1 week of the indicated month of lactation.

\section{Milk sampling}

Milk samples $(\leq 1 \mathrm{ml})$ were collected before and after each feed from each breast over a $24-28 \mathrm{~h}$ period by either manual breast pump (Kaneson Expression and Feeding Bottle, Yanasem Waitch K.K., Osaka, Japan) or hand expression into $5 \mathrm{ml}$ polypropylene vials (Disposable Products Pty Ltd., Adelaide, South Australia, Australia). Samples were initially stored in a household freezer for a maximum of $24 \mathrm{~h}$ and then transported on ice to the laboratory, where they were stored at $-20^{\circ} \mathrm{C}$ until analysis.

\section{Determination of $24 \mathrm{~h}$ milk production}

Milk yield was determined for each breast by test weighing the mother, accounting for insensible water loss as described by Arthur et al. (1987). Test weighing was carried out at each mother's home over the same $24-28 \mathrm{~h}$ period that milk samples were collected using an electronic Sauter balance (weighing platform, model EC 240; evaluator unit with data output printer, model ED 3300; FSEM Scientific, Perth, Western Australia, Australia). Briefly, mothers weighed themselves before and after each feed from each breast. To account for the insensible water loss incurring during feeding, mothers were instructed to reweigh themselves $20 \mathrm{~min}$ after the end of each feeding session. The rate of water loss for this $20 \mathrm{~min}$ period was then used to calculate insensible water loss during the feeding period. Final corrected $24 \mathrm{~h}$ milk yield was calculated from the data collected over the $24-28 \mathrm{~h}$ period using the method described by Arthur et al. (1987).

\section{Biochemical analyses}

Milk fat. The fat content of the fore- and hindmilk samples was determined using the modified method of
Stern \& Shapiro (1953) as described by Cox et al. (1996). Briefly, $2.5 \mu \mathrm{l}$ milk samples (warmed to $37^{\circ} \mathrm{C}$ ) and standards $(0-200 \mathrm{~mm}$-triolein $)$ were added to redistilled ethanol $(600 \mu \mathrm{l})$ and mixed for $10 \mathrm{~s}$. Hydroxylamine hydrochloride $(2 \mathrm{M}, 100 \mu \mathrm{l})$ and $\mathrm{NaOH}(3.5 \mathrm{M}$, $100 \mu \mathrm{l})$ were then added to each sample and the samples mixed and left to stand at room temperature for $20 \mathrm{~min}$. Each sample was acidified by the addition of $\mathrm{HCl}$ $(4 \mathrm{M}, 100 \mu \mathrm{l})$ and colour production achieved by the addition of a $\mathrm{FeCl}_{3}-\mathrm{TCA}$ solution $(7.5 \mathrm{~g}$ TCA in $10 \mathrm{ml}$ $\left.0 \cdot 37 \mathrm{M}-\mathrm{FeCl}_{3}-0.1 \mathrm{M}-\mathrm{HCl}, \quad 100 \mu \mathrm{l}\right)$. The tubes were mixed and $250 \mu \mathrm{l}$ was pipetted into duplicate wells on a ninety-six-well microtitre plate. The absorbance of each well was determined at $540 \mathrm{~nm}$ using a plate spectrophotometer. The detection limit of this assay was 0.45 $(\operatorname{SEM} 0.41) \mathrm{g} / \mathrm{l}(n \mathrm{13})$ and the interassay $\mathrm{CV}$ was $8.1 \%$ (n 13).

Fatty acid composition. FA were extracted with chloroform-methanol $(2: 1, \mathrm{v} / \mathrm{v})$ using butylated hydroxyanisole as an antioxidant, according to the modified method of Folch et al. (1957; Gibson \& Kneebone, 1981). FA methyl esters from milk lipid extracts were prepared by acid transmethylation using $\mathrm{H}_{2} \mathrm{SO}_{4}(10 \mathrm{ml} / \mathrm{l}$ in methanol) according to a modified method of Christie (1973). FA methyl esters were separated using a GC (Shimadzu GC-14A, Shimadzu Corporation, Kyoto, Japan) equipped with a $50 \mathrm{~m}$ capillary column $(0 \cdot 32 \mathrm{~mm}$ internal diameter) coated with BPX-70 $(0.25 \mu \mathrm{m}$ film thickness; SGE Pty Ltd, Ringwood, Victoria, Australia) using a method modified from that of Makrides et al. (1995). Each sample $(3 \mu \mathrm{l})$ was injected onto the column using an automatic injector (Shimadzu AOC-14; Shimadzu Corporation) at a split ratio of $30: 1$. The injector temperature was set at $250^{\circ} \mathrm{C}$ and the detector (flame ionisation) temperature at $300^{\circ} \mathrm{C}$. The initial oven temperature was $140^{\circ} \mathrm{C}$ and was programmed to rise to $230^{\circ} \mathrm{C}$ at $5^{\circ} \mathrm{C} / \mathrm{min}$. The carrier gas was $\mathrm{He}$ at a velocity of $4 \mathrm{ml} /$ min. FA were identified based on retention time to authentic lipid standards (Nu-Chek-Prep Inc., Elysian, MN, USA).

The CV of the proportions of $12: 0,16: 0,18: 1 n-9$, $18: 2 n-6$ and $22: 6 n-3$ over five separate extractions were $6 \cdot 30,0.82,1.08,0.98$ and $3.10 \%$ respectively. The $\mathrm{CV}$ of the proportions of $12: 0,16: 0,18: 1 n-9,18: 2 n-6$ and $22: 6 n-3$ over five separate GC injections were $3 \cdot 49$, $0.30,0.49,0.60$ and $1.90 \%$ respectively. The recovery of 17:0 (added as triheptadecanoic acid) to milk prior to extraction with respect to the addition of 15:0 (added as a methyl ester after transesterification) was 101.4 (SEM 2.26) \% (n 6).

\section{Determination of $24 \mathrm{~h}$ fatty acid intake}

For each feed from each breast, the fat contents of foreand hindmilk samples were averaged to provide the fat content for each feed. The volume of the feed was then used to determine the amount of fat consumed by the infant at each feed. This amount, together with the FA composition of that feed, as determined by GC, was then used to determine the amount of individual FA consumed by the infant. The sum of the amounts of each FA provided 
by all feeds over the study period $(24-28 \mathrm{~h})$ and the total volume of milk consumed by the infant over the study period were then used to determine an average concentration $(\mathrm{g} / \mathrm{l})$. This concentration and the corrected $24 \mathrm{~h}$ volume (Arthur et al. 1987) were then used to determine the amount consumed in $24 \mathrm{~h}$ by the infant.

\section{Statistical analysis}

All longitudinal analyses were performed using the SAS System for Windows, version 6.12 (SAS Institute Inc., Cary, NC, USA) with the general linear means (PROC GLM) procedure. The GLM longitudinal analyses for the composition of FA were weighted for the number of observations for each woman, at each time point. Student's paired $t$ tests and other statistics were performed using Statview ${ }^{\mathrm{TM}}$ SEM + Graphics (Abacus Concepts Inc., Berkeley, CA, USA). All values are reported as means with their standard errors unless otherwise stated. Differences with $P$ values $<0.05$ were considered significant.

\section{Results}

\section{Breast-feeding characteristics}

The mean age and parity of the participating mothers was 33.00 (SEM 1.30) years and 2.60 (SEM 0.24) children respectively. Mean daily milk production for all mothers over the course of the year (five mothers, months 1, 2, 4, 6, 9 and 12, $n$ 30) was 336.60 (SEM 26.21) $\mathrm{ml}$ for the left breast and 414.49 (SEM 28.39) $\mathrm{ml}$ for the right breast and did not differ over the course of the year (Table 1). The mean daily fat content for all mothers over the course of the year was 36.06 (SEM 1.37) g/l for the left breast and 34.97 (SEM 1.50) $\mathrm{g} / \mathrm{l}$ for the right breast and differed over the course of the year $(P<0.05)$. This corresponded to the baby receiving 12.08 (SEM 0.89 ) $\mathrm{g}$ fat per $24 \mathrm{~h}$ from the left breast and 13.63 (SEM 0.88) g fat per $24 \mathrm{~h}$ from the right breast.

\section{Fatty acid composition}

There was no significant difference in the proportional composition of FA in fore- and hindmilk. Therefore, subsequent analyses of FA composition for left and right breasts were performed on hindmilk samples only. FA composition did vary over the course of the day: the mean daily CV for all FA identified was 14.3 (SEM 7.7) $\%$. The pattern of daily variation of individual FA was not conserved either between women or over the course of lactation (Fig. 1).

The observed variation in the composition of $10: 0$, $12: 0,14: 0,16: 0,18: 0,18: 1 n-9,18: 2 n-6,18: 3 n-3$, $20: 4 n-6$ and $22: 6 n-3$ between women and over the course of lactation was significant $(P<0.05)$ in all cases (Table 2). Over the course of lactation, the medium-chain FA 10:0,12:0 and 14:0 all decreased with time to 6 months $(P<0.0001)$. Following this, $12: 0$ and 14:0 increased markedly towards 12 months $(P<0.0001)$ whilst 10:0 remained constant. Palmitic acid (16:0) 
(A)

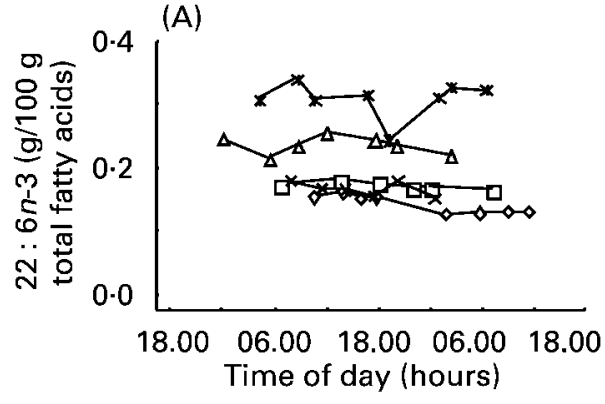

(C)

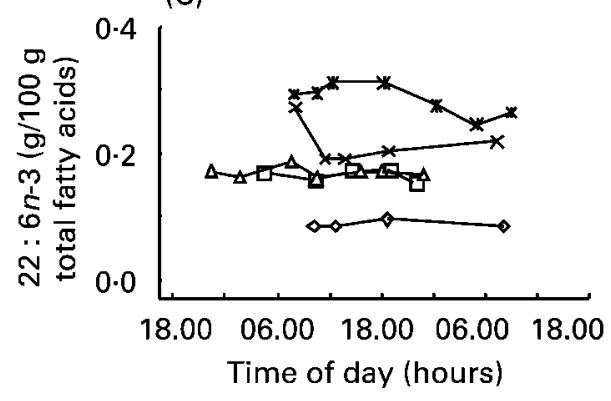

(E)

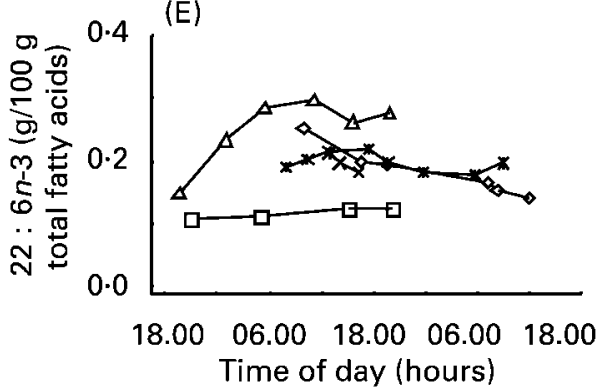

(B)

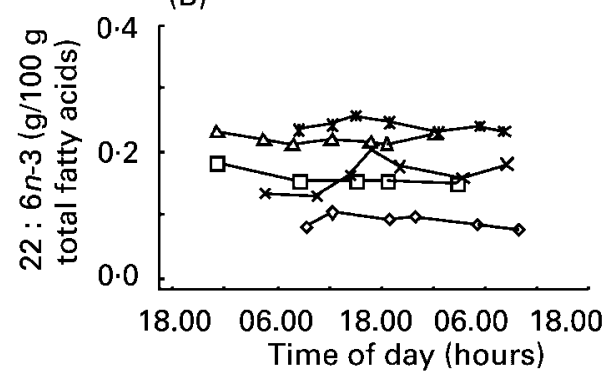

(D)
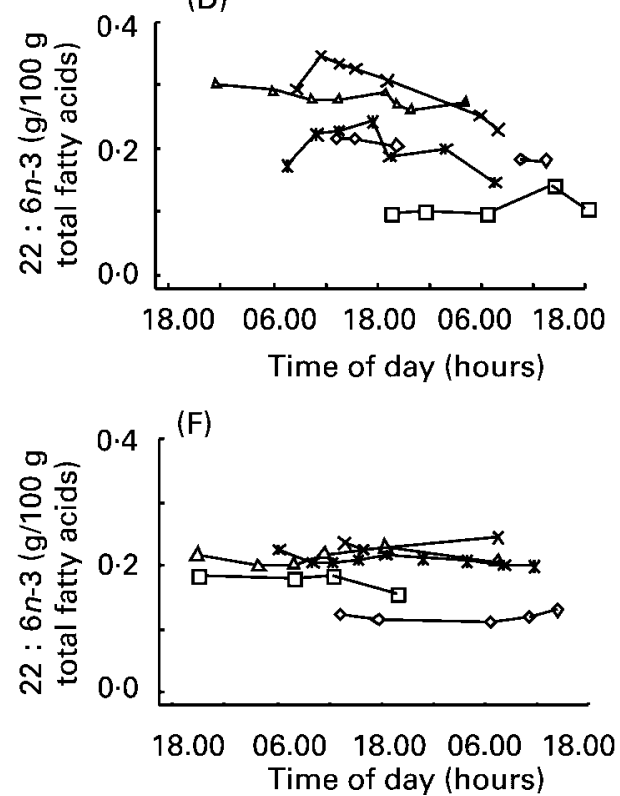

Fig. 1. Variation in the proportion of $22: 6 n-3$ in milk from each feed from the left breast over a $24 \mathrm{~h}$ period for five mothers at 1 (A), 2 (B), $4(\mathrm{C}), 6(\mathrm{D}), 9(\mathrm{E})$ and $12(\mathrm{~F})$ months of lactation. $\diamond$, Mother $1 ; \square$, mother $2 ; \triangle$, mother $3 ; \times$, mother $4 ; *$, mother 5 . Fatty acid composition varied over the course of the day, but this variation was not consistent between mothers or over the course of lactation. For details of subjects and procedures, see p. 980 .

behaved similarly to $10: 0$, showing an initial decrease towards 4 months $(P<0 \cdot 0001)$ and then remaining constant to 12 months of lactation. Although not a medium-chain FA, 18:0 followed a similar trend to $12: 0$ and 14:0, decreasing towards 9 months $(P<0 \cdot 0001)$ and then increasing from 9 to 12 months of lactation $(P<0 \cdot 0001)$.

For $18: 1 n-9$, there was no difference in the proportional composition between the values obtained at 1 and 12 months. However, $18: 1 n-9$ did increase towards 6 months $(P<0.0001)$ before decreasing towards 12 months $(P<0 \cdot 0001)$. Linoleic acid $(18: 2 n-6)$ also followed this trend by increasing towards 6-9 months $(P=0 \cdot 0001)$ and then decreasing at 12 months of lactation $(P<0.05)$. Linolenic acid (18:3n-3) increased towards 6-9 months $(P<0.0001)$ and then remained constant to 12 months. Arachidonic acid (20:4n-6) decreased towards 6 months and then remained constant to 12 months $(P=0 \cdot 0006)$. Docosahexaenoic acid (22:6n-3) decreased from 1-2 months $(P=0 \cdot 0002)$, after which there was an increase towards 6 months $(P<0 \cdot 0001)$ followed by no change through to 12 months.

\section{Amounts of fatty acids consumed by the infant}

On average, over the first year of lactation, the greatest amount of any individual FA consumed by the infant over the $24 \mathrm{~h}$ period was that of $18: 1 n-9(8.27$ (SD 2.84) g/ $24 \mathrm{~h})$. The infant also consumed both the $n-6$ and $n-3$ essential FA $18: 2 n-6(2 \cdot 38$ (SD 0.98) g/24h) and $18: 3 n-3(0 \cdot 19$ (SD 0.07$) \mathrm{g} / 24 \mathrm{~h}$ ) respectively. The infant consumed 92.5 (SD $31 \cdot 1) \mathrm{mg}$ arachidonic acid $(20: 4 n-6) / 24 \mathrm{~h}$ and $49 \cdot 3$ (SD 21.1) mg $22: 6 n-3 / 24 \mathrm{~h}$. Overall, the infant consumed 12.14 (SD 4.29) g saturated FA/24h and 3.58 (SD 1.07) $\mathrm{g}$ polyunsaturated FA/24h, of which 3.22 (SD 0.95) g was of the $n-6$ family and 0.3 (SD $0 \cdot 11$ ) g was from the $n-3$ family. This gave a ratio of 8.9 (SD 1.94) for the consumption of the $n-6$ FA : $n-3$ FA. The infant also consumed 0.62 (SD 0.35) g trans FA/24h.

The amounts of major individual FA of interest $(10: 0$, $12: 0,14: 0,16: 0,18: 0,18: 1 n-9,18: 2 n-6,18: 3 n-3$, $20: 4 n-6$ and $22: 6 n-3)$ consumed by the infant during the first year of lactation showed no significant difference with time (Table 3). Only the intakes of $22: 1 n-9$, 


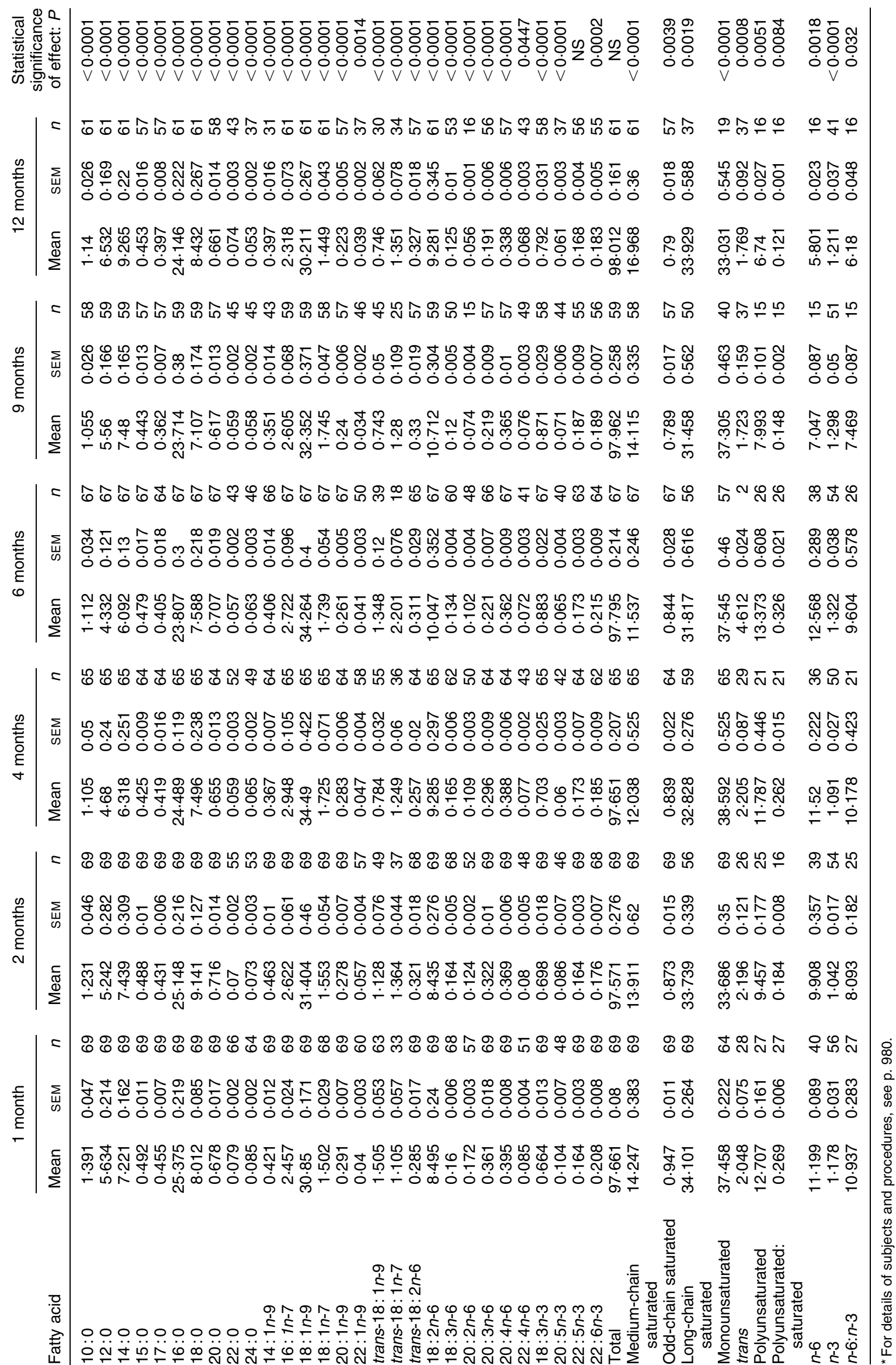




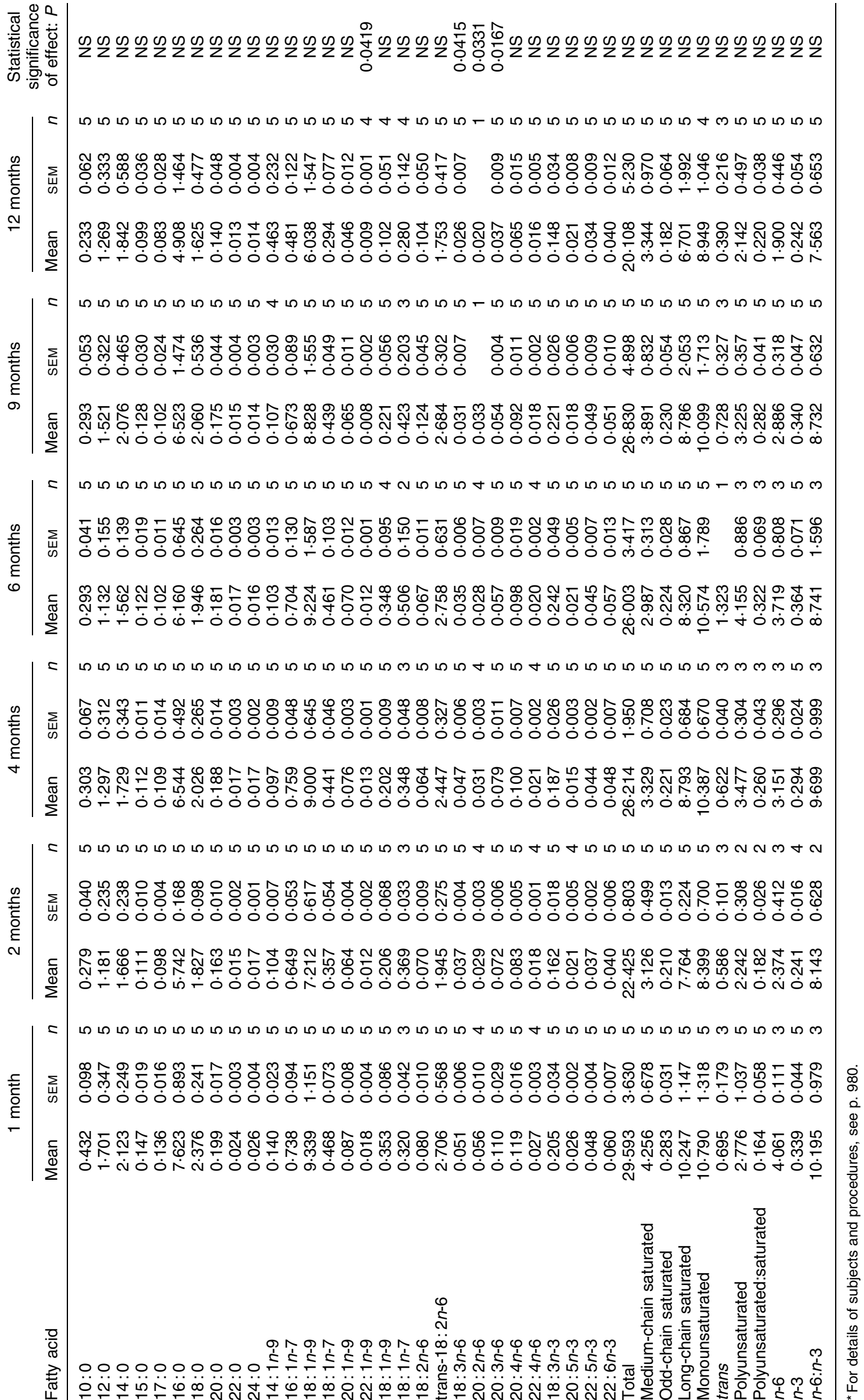


$18: 3 n-6,20: 2 n-6$ and $20: 3 n-6$ differed with time over the first year of lactation $(P<0 \cdot 05)$. Furthermore, there were no differences between infants in amounts of the FA consumed, except for the $n-3$ FA: $18: 3 n-3,22: 5 n-3$ and $22: 6 n-3$.

\section{Discussion}

The FA composition of milk was found to vary over the course of the day (Fig. 1) and this finding is in agreement with previous results from this laboratory (Daly et al. 1993), but in contrast to reports in the literature (Hall, 1979; Jensen, 1989). Hall (1979) found no evidence of a circadian rhythm in FA composition in human milk samples taken at regular time points over $3 \mathrm{~d}$. However, upon closer inspection of Hall's results, FA composition did vary, with some FA showing daily $\mathrm{CV}$ of up to $40 \%$. The current results agree with those of Hall (1979); however, the interpretation differs, as Hall was specifically looking for a circadian rhythm. The lack of a circadian rhythm, however, does not preclude the FA composition from changing in a regulated manner over the course of the day, as was the case with the results of Daly et al. (1993).

The FA composition varied between the five mothers in the present study and with time over the first year of lactation (Table 2). Differences between mothers were expected and are well documented, and are most likely to be due to differences in maternal diet (Jensen, 1989). Reports on longitudinal changes in FA composition over the course of lactation are not as common; furthermore, there is a lack of consistency in the results in the literature. For example, the two essential FA $(18: 2 n-6$ and $18: 3 n-3)$ increased at 6-9 months of lactation. Similar trends were observed up to 3 (Huisman et al. 1996), 6 (Luukkainen et al. 1994) and 8 (Idota et al. 1991) months of lactation. However, Makrides et al. (1995) showed no change in either FA over 7.5 months ( 30 weeks) of lactation, whereas Marangoni et al. (2000) showed differences over 12 months but no specific trend. Similar differences in the literature can be found for other FA and these results highlight the complex nature of the relationships between individual FA in human milk and clearly suggest a need for future research investigating the regulation of FA incorporation into breast milk.

Whilst much recent interest has focused on infant longchain polyunsaturated FA status, few studies have actually investigated infant FA intake (Marangoni et al. 2000). An important feature of the current study was the ability of the sampling method of Hartmann et al. (1986) to allow the conversion of concentrations of individual FA into amounts consumed by the infant. Changes in the amounts of specific FA $(10: 0,12: 0,14: 0,16: 0,18: 0,18: 1 n-9$, $18: 2 n-6,18: 3 n-3,20: 4 n-6$ and $22: 6 n-3)$ delivered to the infant in a $24 \mathrm{~h}$ period over the first year of life (Table 3) showed no significant differences with stage of lactation. Furthermore, of these FA, only the $n$ - 3 FA differed between women. This is in contrast to changes in the proportional composition of FA: all of these FA were different both between women and over the course of lactation, as was also shown by Marangoni et al. (2000). These results suggest that variation in the proportional composition of individual FA cannot be translated to variation in infant intake. Intake needs to be determined directly using FA concentration and milk production. Therefore, changes in the composition of FA (either between women or with time) can be compensated for by changes in milk intake by the infant. It is interesting to note that only the $n-3$ long-chain polyunsaturated FA were different between women, perhaps suggesting the dependence of these FA on immediate diet as opposed to body depots (Del Prado et al. 2000).

Estimated whole-body $22: 6 n-3$ requirement rates of 20 (Cunnane et al. 2000) and 30 (Farquharson et al. 1993) $\mathrm{mg} / 24 \mathrm{~h}$ are below the mean infant intakes recorded in the current study (Table 3). Furthermore, the mean $24 \mathrm{~h}$ infant intake of $22: 6 n-3$ of 49 (SEM 21) mg/24h determined in the current study agrees with the reported estimated intakes of 50 (Hachey, 1994) and 60 (Cunnane et al. 2000) $\mathrm{mg} / 24 \mathrm{~h}$ by the breast-fed infant. These results suggest that the five breast-fed infants in the present study had access to a surplus of preformed $22: 6 n-3$ and in this regard they are probably representative of the average, term-delivered, exclusively breast-fed infant from 1 to 6 months of age. However, the present study cannot establish whether or not these intake levels are sufficient or indeed 'optimal', because of the limited number of subjects and the lack of any outcome measures. Further studies are required to associate actual infant intakes of specific FA, as opposed to breast-milk concentrations, with specific functional outcomes before formal dietary recommendations can be made.

In conclusion, the FA composition of milk determined in the current study was similar to that previously reported (Jensen et al. 1995). In contrast to the study of Jensen et al. (1995), we observed that the FA composition did vary over the short-term; however, there was no consistent pattern (circadian or otherwise) in FA variation. It is, therefore, recommended that this variation together with the variation in total fat content (Mitoulas et al. 2002) be accounted for by the use of a suitable sampling protocol, i.e. similar to that of Hartmann et al. (1986), when investigating infant FA intakes. FA composition also varied over the long-term; however, the variation in FA composition both between women and with stage of lactation was not conserved when amounts of FA consumed by the infant per $24 \mathrm{~h}$ were investigated. Therefore, it is important to recognise that changes in the proportions of individual FA may not necessarily result in commensurate changes in $24 \mathrm{~h}$ infant intake of those FA, and that intake must be measured directly if the effects of altering milk FA composition are to be correlated with infant functional outcomes.

\section{Acknowledgements}

The authors thank the mothers and babies who participated in this study, together with the Australian Breastfeeding Association. We also thank Dijana Mihic and Tracey Williams for technical assistance. This study was supported by the Grains Research and Development Corporation of Australia, Meadow Lea Foods Ltd, Medela AG, the Lotteries 
Commission of Western Australia, and the National Health and Medical Research Council of Australia.

\section{References}

Arthur PG, Hartmann PE \& Smith M (1987) Measurement of the milk intake of breast-fed infants. J Pediatr Gastroenterol Nutr 6, 758-763.

Butte NF, Garza C, Smith EO \& Nichols BL (1984) Human milk intake and growth in exclusively breast-fed infants. $J$ Pediatr 104, 187-195.

Christie WW (1973) Lipid analysis. Isolation, Separation, Identification and Structural Analysis of Lipids. Oxford: Pergamon Press.

Cox DB, Kent JC, Casey TM, Owens RA \& Hartmann PE (1999) Breast growth and the urinary excretion of lactose during human pregnancy and early lactation: endocrine relationships. Exp Physiol 84, 421-434.

Cox DB, Owens RA \& Hartmann PE (1996) Blood and milk prolactin and the rate of milk synthesis in women. Exp Physiol 81, $1007-1020$.

Cunnane SC, Francescutti V, Brenna JT \& Crawford MA (2000) Breastfed infants achieve a higher rate of brain and whole body docosahexaenoate accumulation than formula-fed infants not consuming dietary docosahexaenoate. Lipids 35, 105-111.

Daly SEJ, Di Rosso A, Owens RA \& Hartmann PE (1993) Degree of breast emptying explains changes in the fat content, but not fatty acid composition, of human milk. Exp Physiol 78, 741-755.

Del Prado M, Villalpando S, Lance A, Alfonso E, Demmelmair H \& Koletzko B (2000) Contribution of dietary and newly formed arachidonic acid to milk (secretion in women on low fat diets). In Short and Long Term Effects of Breast Feeding on Child Health, pp. 407-408 [B Koletzko, KF Michaelson and O Hernell, editors]. New York: Kluwer Academic/Plenum Publishers.

Farquharson J, Cockburn F, Patrick WA, Jamieson EC \& Logan RW (1993) Effect of diet on infant subcutaneous tissue triglyceride fatty acids. Arch Dis Child 69, 589-593.

Folch J, Lees M \& Sloane Stanley GH (1957) A simple method for the isolation and purification of total lipides from animal tissues. J Biol Chem 226, 497-509.

Gibson RA \& Kneebone GM (1981) Fatty acid composition of human colostrum and mature breast milk. Am J Clin Nutr 34, 252-257.

Gibson RA \& Makrides M (2000) $n$-3 Polyunsaturated fatty acid requirements of term infants. Am J Clin Nutr 71, Suppl., 251S-255S.

Gibson RA, Neumann MA \& Makrides M (1996) Effect of dietary docosahexaenoic acid on brain composition and neural function in term infants. Lipids 31, Suppl., S177-S181.

Hachey DL (1994) Benefits and risks of modifying maternal fat intake in pregnancy and lactation. Am J Clin Nutr 59, Suppl., 454S-463S.

Hall B (1979) Uniformity of human milk. Am J Clin Nutr 32, 304-312.

Hartmann PE, Mitoulas LR \& Sherriff JL (2000) Synthesis and secretion of fat in human milk and its role in infant development. J Integr Study Diet Habits 10, 65-73.

Hartmann PE, Morgan SEG \& Arthur PG (1986) Milk let-down and the concentration of fat in breast milk. In Human Lactation 2: Maternal and Environmental Factors, pp. 275-281
[M Hamosh and AS Goldman, editors]. New York: Plenum Press.

Huisman M, van Beusekom M, Lanting CI, Nijeboer HJ, Muskiet FA \& Boersma ER (1996) Triglycerides, fatty acids, sterols, mono- and disaccharides and sugar alcohols in human milk and current types of infant formula milk. Eur J Clin Nutr 50, $255-260$.

Hytten FE (1954) Clinical and chemical studies in human lactation: I. Collection of milk samples. II. Variation in major constituents during feeding. III. Diurnal variation in major constituents in milk. Brit Med J 23, 175-182.

Idota T, Sakurai M, Sugawara Y, et al. (1991) The latest survey for the composition of milk obtained from Japanese mothers. Part II. Changes of fatty acid composition, phospholipid and cholesterol contents during lactation. Jpn J Pediatr Gastroenterol Nutr 5, 159-173.

Innis SM, Gilley J \& Werker J (2001) Are human long-chain polyunsaturated fatty acids related to visual and neural development in breast-fed term infants? J Pediatr 139, 532-538.

Innis SM \& Kuhnlein HV (1988) Long chain $n$-3 fatty acids in breast milk of Inuit women consuming traditional foods. Early Hum Dev 18, 185-189.

Isaacs CE, Thormar H \& Pessolano T (1986) Membrane-disruptive effect of human milk: inactivation of enveloped viruses. J Infect Dis 154, 966-971.

Jensen RG (1989) The Lipids of Human Milk. Boca Raton, FL: CRC Press.

Jensen RG, Bitman J, Carlson SE, Couch SC, Hamosh M \& Newberg DS (1995) Milk Lipids. In Handbook of Milk Composition, pp. 495-576 [RG Jensen, editor]. San Diego, CA: Academic Press.

Kent JC, Mitoulas LR, Cox DB, Owens RA \& Hartmann PE (1999) Breast volume and milk production during extended lactation in women. Exp Physiol 84, 435-447.

Kneebone GM, Kneebone R \& Gibson RA (1985) Fatty acid composition of breast milk from three racial groups from Penang, Malaysia. Am J Clin Nutr 41, 765-769.

Luukkainen P, Salo MK \& Nikkari T (1994) Changes in the fatty acid composition of preterm and term human milk from 1 week to 6 months of lactation. J Pediatr Gastroenterol Nutr 18, 355-360.

Makrides M, Simmer K, Neumann MA \& Gibson RA (1995) Changes in the polyunsaturated fatty acids of breast milk from mothers of full term infants over $30 \mathrm{wk}$ of lactation. Am J Clin Nutr 61, 1231-1233.

Marangoni F, Agostoni C, Lammardo AM, Giovannini M, Galli C \& Riva E (2000) Polyunsaturated fatty acid concentrations in human hindmilk are stable throughout 12-months of lactation and provide a sustained intake to the infant during exclusive breastfeeding: an Italian study. Brit J Nutr 84, 103-109.

Mitoulas LR, Kent JC, Cox DB, Owens RA, Sherriff JL \& Hartmann PE (2002) Variation in fat, lactose and protein in human milk over $24 \mathrm{~h}$ and throughout the first year of lactation. Brit J Nutr 88, 29-37.

Read WWC, Lutz PG \& Tashjian A (1965) Human Milk Lipids II. The influence of dietary carbohydrates and fat on the fatty acids of mature milk. A study in four ethnic groups. Am J Clin Nutr 17, 180-183.

Stern I \& Shapiro B (1953) A rapid and simple method for the determination of esterified fatty acids and for total fatty acids in blood. J Clin Pathol 6, 158. 